\title{
As quatro figuras da "sexualidade" nos colonialismos de povoamento*
}

\author{
Elizabeth A. Povinelli**
}

Coisas que sabemos. O primeiro volume da História da Sexualidade de Michel Foucault termina com uma discussão de três formações de poder que ele acreditava que definiam a história do poder (liberal) moderno - soberania, disciplina e biopoder. Conforme Foucault, os dois últimos poderes nos permitem "entender a importância adquirida pelo sexo como uma questão política", na medida em que "sexo era tanto um acesso à vida do corpo quanto à vida da espécie" (Foucault, 1978:145, 146).

Em outras palavras, sexualidade - e gênero - não interessavam a Foucault em si mesmos, mas apenas em relação a como o poder moderno se organizara em torno de uma "tecnologia da vida" (Foucault, 1978:145). O mesmo se passa com as quatro figuras e estratégias da sexualidade: a mulher histérica (histericização dos corpos femininos); a criança que se masturbava (pedagogização do sexo infantil); o adulto perverso (psiquiatrização do prazer perverso); e o casal maltusiano (socialização do comportamento procriativo). A razão pela qual Foucault se interessava por sexualidade e gênero, e suas figurações e estratégias discursivas, era que ele se interessava pelas formações do poder moderno no âmbito do qual vivia.

Outras coisas que sabemos. Foucault publicou o que seria o primeiro volume da História da Sexualidade quando estava fazendo a primeira de suas conferências sobre biopoder no Collège de France. Ao longo das duas primeiras conferências, Em

\footnotetext{
* Recebido para publicação em 25 de junho de 2013, aceito em 28 de julho de 2013. Tradução: Mariza Corrêa.

** Professor, Department of Anthropology, Columbia University. ep2122@columbia.edu
}

cadernos pagu (41), julho-dezembro de 2013:11-18. 
As quatro figuras da "sexualidade" nos colonialismos de povoamento

defesa da sociedade e Segurança, Território, População, Foucault fez um contraste ainda mais dramático sobre como a ideia do povo como fundação da democracia moderna teve de ceder lugar a uma análise da população. $O$ povo pode ser o fundamento ideológico da diferença liberal democrática, mas, de um ponto de vista analítico, a gestão da população era a fonte fundadora de sua legitimidade e razão. ${ }^{1}$ Assim, em Em defesa da sociedade, Foucault não apenas retira o foco de seus ouvintes do imaginário dos direitos soberanos dos reis, mas da soberania do "povo". Quando estava discorrendo sobre Segurança, Território, População, Foucault explicitamente contrastava o controle da população à insurreição do povo. Quem é o povo? pergunta Foucault. Eles não são soberanos;

o povo são aqueles que se conduzem em relação à gestão da população, ao nível da população, como se não fossem parte da população como um coletivo sujeito-objeto, como se se colocassem fora dela, e, consequentemente, o povo são aqueles que, recusando ser a população, perturbam o sistema (Foucault, 2009:43,44).

$\mathrm{O}$ que podemos deduzir. Como em relação à sexualidade também em relação à raça, Foucault não estava interessado no racismo, nem mesmo na questão da raça em si mesma, mas só em como ela podia ajudá-lo a compreender o quanto a raça era animada no âmbito de formações específicas do poder, isto é, nas intersecções do biopoder, da disciplina e da soberania no caso do Holocausto judeu. ${ }^{2}$ Assim, mesmo se Ann Stoler (1995) estivesse

1 Como no caso de Ernesto Laclau (2005:153) para quem "a construção de um "povo" é "a operação política par excellence" na democracia.

2 "O problema que gostaria de ter posto é outro, e não diz respeito ao racismo, nem, em primeira instância, ao problema das raças. Tratava-se - e, para mim, ainda se trata - de tentar ver como surgiu no Ocidente, uma certa análise (crítica, histórica e política) do Estado, de suas instituições e de seus mecanismos de poder." (Foucault, Em defesa da sociedade, p.75). 
certa ao observar que a raça não emergiu no interior da Europa, mas nos espaços imperiais, o que estava em jogo não era que o poder racializado estivesse antes em outros lugares, mas que novas formações de poder aparecem e assim animam a sua diferença nesses espaços. Este é o projeto necropolítico de Achille Mbembe (2003), que pretende não apenas demonstrar as origens diversas do biopoder moderno, mas também questionar sua aplicação ao longo de tempos e espaços históricos e de elaborar formações diferentes de poder, isto é, como vários espaços coloniais permitiram experimentos instrumentais $e$ prazeres psíquicos no poder de massacrar. ${ }^{3}$ Assim perguntar-se como as teorias de Foucault sobre sexualidade e gênero, raça e poder podem ser relevantes para a nossa compreensão do colonialismo de povoamento e do nativismo, é perguntar quais são as formações de poder $e$ as figuras de discurso relevantes para um governo (liberal) dos povoadores - e se raça ou sexo são figuras, ou estratégias, chaves.

Para isso, farei as seguintes três propostas que, espero, podem levar a algumas coisas que ainda não sabemos como saber.

Primeiro, se queremos entender como a sexualidade $e$ a raça são maneiras de regular e conformar a vida de corpos nativos e das populações nas colônias de povoamento liberais, devemos começar por olhar além da sexualidade e da raça. No lugar disso, devemos examinar os discursos múltiplos de liberdade individual e autodeterminação, e do controle e constrangimento social que animam como as relações $e$ as figuras sexuais aparecem, enquadram $e$ administram as lutas entre os povoadores $e$ os nativos. Em Empire of love chamei esses dois discursos, respectivamente, de autologia e genealogia e procurei demonstrar que eles não são fatos no mundo, mas métodos para dividir o mundo e assim constituir dois tipos de verdade sobre os sujeitos e

${ }^{3}$ Embora Mbembe não chame essa formação de o "poder para massacrar" ("power to slaughter") me parece que a palavra inglesa slaughter cruza a natureza instrumental e a psíquica das formas de morticínio colonial que ele estava tentando descrever (Mbembe, 2003:11-40). 
As quatro figuras da "sexualidade" nos colonialismos de povoamento

seus mundos sociais. Sociedades autológicas e genealógicas são constituídas como nitidamente separadas, moralmente opostas, e temporariamente como a face de Jano, lançando-as contra dois horizontes temporais. Diz-se do autológico que orienta normativamente o desvelamento horizontal da verdade; o genealógico está vinculado ao passado perfeito da repetição tradicional. Sexualidade e gênero, intimidade e raça, não precedem esses mecanismos de divisão, mas, ao invés disso, são animados por eles, recebendo conteúdo, sendo circulados e dispersos.

Um ponto que levantei em Empire of Love, mas que enfatizei e elaborei em Economies of Abandonment, é que os discursos de autologia e genealogia são mais visíveis quando vistos da perspectiva do colonialismo de povoamento. A separação entre formas de governo reais e aristocráticas, o que Foucault chamaria de poder soberano, era projetada na separação entre as assim chamadas sociedades democráticas e tradicionais, $e$ fora delas, nos espaços coloniais e imperiais - mas institucionalmente explícita nas colônias de povoamento. Assim como o imaginário do poder real e aristocrático, o imaginário das sociedades tradicionais seria orientado pelo passado, determinado pelos costumes e pelo cerceamento individual. E o imaginário da sociedade moderna seria o futuro perfectível, horizontal $e$ autodeterminado. Esses imaginários de conjugação se mantêm firmes, seja operando no âmbito das técnicas de exterminação, de reconhecimento ou de assimilação. Assim, no caso australiano, os discursos de conjugação, estriando a divisão entre o autológico e o genealógico, tornam-se habilitados a legitimar o extermínio, a assimilação, a autodeterminação (a expressão para reconhecimento cultural $e$ a era de direitos sobre a terra) e, mais recentemente, um assalto dirigido de pânico sexual contra a autodeterminação. ${ }^{4}$

É no âmbito dessa divisão entre o autológico e o genealógico, mais do que no da raça per se, que o direito de

${ }^{4}$ Para uma discussão mais elaborada desse ponto, ver Povinelli (2010). 
matar, de manter vivo ou deixar morrer, é expresso e legitimado nas colônias de povoamento.

Em segundo lugar, se queremos entender o papel governamental que o discurso sobre a população tem nas colônias de povoamento, a análise da população deve ser situada no âmbito do que estou chamando de governo do imaginário do carbono. Talvez seja mais fácil e mais eficiente dizer o que quero dizer com imaginário de carbono através da Grande Cadeia dos Seres. Como sabemos, várias versões da Grande Cadeia dos Seres - incluindo a história conjetural - não apenas absorveram todas as espécies num esquema cosmológico regulador, como todas as populações humanas num modo de governo imperial e colonial.

Mas menos do que um rompimento entre os animais humanos e não humanos ou entre os vários tipos de sociedades humanas, a análise do biopoder (população) nas colônias de povoamento precisam pressionar o rompimento entre $\mathrm{o}$ geológico/mineral existente (matéria) e a vida biológica. Precisamos questionar o momento no qual um modo de existência - o fato do nascimento, crescimento, potencial reprodução, e morte - é capaz de se separar de outro modo de existência que parece não passar por esses processos.

Creio que precisamos fazer isso porque as divisões entre o geológico e o biológico animam o senso comum epistemológico e ontológico em todas as ciências naturais e sociais, a crítica e a literatura, a política e o mercado. As ciências da vida notoriamente assim nomeadas - lutam para compreender o processo através do qual a matéria geológica conquistou as funções e as dinâmicas do metabolismo, logo, da vida; ao lutar para demonstrar a mecânica desse ramo emergente, a pressuposição de suas diferenças mostra ainda mais as profundas diferenças entre as técnicas e estratégias, não apenas da ciência da natureza, mas da política da mudança climática. $\mathrm{O}$ deserto é visto como ser, mas não como vida. O mesmo acontece com as ciências filosóficas. Derrida (1969:31-57) foi quem mostrou mais claramente como o fim do humano ao mesmo tempo inflacionou 
As quatro figuras da "sexualidade" nos colonialismos de povoamento

o problema de uma forma de ser para o do problema do Ser, e radicalmente deflacionou a preocupação e o cuidado com vastas áreas de pessoas (populações).

Mas a saída para esse dilema tem sido árdua, conforme sugerem as reflexões de Judith Butler (2009:i-xiii) sobre o movimento em seu trabalho da performatividade para a precariedade. Butler nota que em seu trabalho a performatividade implicava em lidar com um relato específico da subjetividade e da 'agency' na qual gênero é equivocadamente tratado como signo de uma verdade inerente, interna, da subjetividade; precariedade

designa a condição politicamente induzida pela qual certas populações sofrem pelas fraquezas das redes sociais $e$ econômicas de amparo e se tornam diferencialmente expostas a injustiças, violência e morte (Butler, 2009:i-xii, ii).

A precariedade, em outras palavras, diz respeito aos seres vivos $e$ assume sua importância a partir de um texto de Spinoza sobre entidades agora vistas como vida - todas as formas de vida podem agora lutar para persistir, mas nem todas recebem apoio.

Mas a divisão do senso comum entre a matéria geológica $e$ a vida biológica restringe os poderes práticos de alguns nativos, mas não apenas as formas nativas de ser, na medida em que as qualidades que animam e asseguram a divisão entre a matéria geológica e a vida biológica não são relevantes nos meus campos de estudos indígenas. Em alguns lugares, digamos, em partes da Austrália indígena, alguma matéria geológica é considerada animada, viva - e outras matérias geológicas também o são potencialmente. Além disso, esse substrato geológico é a condição de outras formas de vida e a medida de seu valor ético e social. Assim, não é a diferença absoluta entre o geológico e o biológico nem o colapso absoluto do geológico e do biológico - digamos nas novas e velhas tradições do vitalismo - que é relevante, mas a pragmática discursiva na qual ser, vida e persistência são postas em prática. Mas essas pragmáticas discursivas diferentes não 
podem ser simplesmente absorvidas nas dinâmicas metabólicas da vida do carbono. Elas não têm as fronteiras $e$ limites fantasmagóricos que o nascimento e a morte emprestam a uma vida; seu envelhecimento segue uma lógica diferente - suas partes podem se dispersar ao invés de desaparecer. O corpo sem vida é seu corpo e assim a biopolítica confronta-se com uma geopolítica não absorvível, a ontologia revela-se ter sido sempre a bioontologia face a uma geo-ontologia não absorvível.

Terceiro, se queremos compreender as formações de poder existentes do ponto de vista das "sociedades tradicionais" ou "nativas" temos de repensar as figuras e estratégias de governo. Podem ser quatro, podem ser duas; certamente existem muitos $e$ variados aglomerados. Mas algumas dessas novas figuras incluem o animista, o terrorista, o deserto e o vírus.

O animista configura uma variedade de posições contrastantes em relação ao imaginário do carbono. $\mathrm{O}$ animista, totêmico, vitalista que recusa não apenas a divisão hierárquica entre humanos e outros animais e a vida das plantas, mas as distinções entre formas de existência enquanto tais.

$\mathrm{O}$ terrorista configura uma variedade de posições contrastantes em relação ao imaginário do carbono e a divisão entre o autológico e o genealógico. O terrorista é o homem bomba verde fantasmagórico e islamista antidemocrático.

O deserto configura a existência como existente, mas não vivida ainda, um ser que não é animado pelo Dasein. O deserto é Marte como futuro da Terra.

$\mathrm{O}$ vírus configura o conhecimento de que o ser humano, e a própria vida, é apenas uma pequena volta de uma força muito mais ampla do surgir e desaparecer, como um repúdio. Esse repúdio, quando se espalha globalmente torna-se a condição de sua própria parada.

Algumas dessas figuras já emergiram como objetos de análise na teoria crítica contemporânea, como no trabalho de Jane Bennett sobre o novo vitalismo e de Jaspir Puar sobre homonacionalismo e o terrorista. Precisamos é de uma teoria do 
As quatro figuras da "sexualidade" nos colonialismos de povoamento

poder que compreenda essas e outras figuras, tais como o vírus e o deserto, como uma abertura sintomática à governabilidade e aos excessos do imaginário do carbono.

\section{Referências bibliográficas}

BuTLER, Judith. Performativity, Precarity and Sexual Politics. Revista de Antropologia Uberoamericana 4 (3), 2009.

DERRIDA, Jacques. The ends of Man. Philosophy and Phenomenological Research 30 (1), 1969.

Foucault, Michel. The History of Sexuality, An Introduction. Vintage, 1978. [Tradução: Robert Hurley].

. Security. Territory, Population: Lectures at the Collège de France 1977-1978. Picador, 2009.

LACLAU, Ernesto. On Populist Reason. Verso, 2005.

MBEMBE, Achille. Necropolitics. Public Culture 15 (1), 2003.

POVINELLI, Elizabeth. Empire of love: toward a theory of intimacy, genealogy and carnality. Durham, Duke, 2006.

POVINELLI, Elizabeth. The Crisis of Culture and the Arts of Care. In: AltMAN, Jon e HinKSON, Melinda (eds.) Culture Crisis -Anthropology and Politics in Aboriginal Australia. University of New South Wales Press, 2010.

POVINELLI, Elizabeth. Economies of abandonment: social belonging and endurance in late liberalism. Durham, Duke, 2011.

StOlER, Ann. Race and the Education of Desire: Foucault's History of Sexualirty and the Colonial Order of Things. Duke, 1995. 